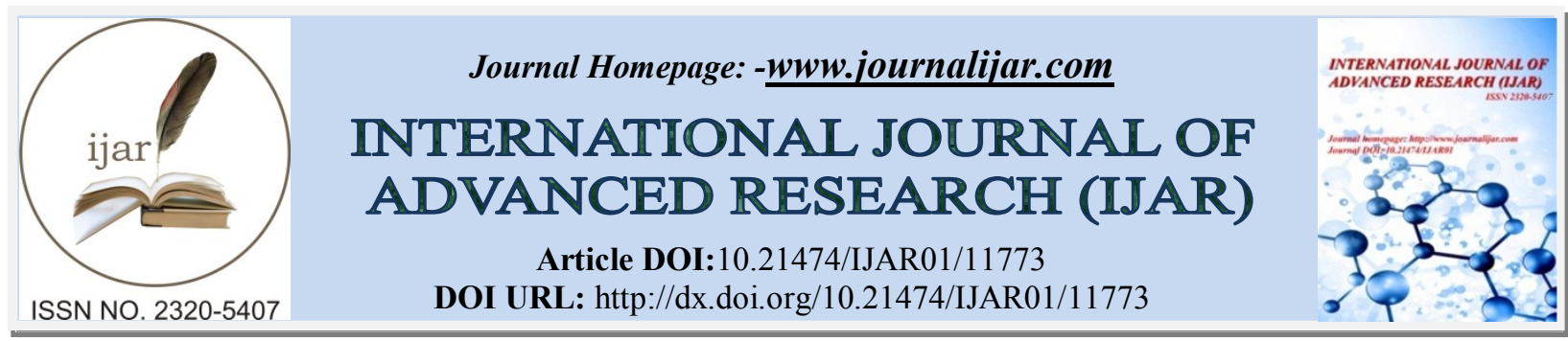

RESEARCH ARTICLE

\title{
EFFECT OF NADIFLOXACIN PHONOPHORESIS AND PULSED ULTRASOUND IN SUBJECTS WITH ACUTE SINUSITIS- A RANDOMIZED CLINICAL TRIAL
}

\section{Anil Rachappa Muragod ${ }^{1}$, Anil S. Harugop ${ }^{2}$, Kirti Khemlapure ${ }^{3}$, Krupa Varahmurty ${ }^{3}$ and Mussarrat Begum Jamkhanewale ${ }^{3}$}

1. Associate Professor, HOD of Geriatric Physiotherapy, KAHER, Institute of Physiotherapy, Belagavi, Karnataka, India.

2. Head of the Department and Professor, E.N.T and H.N.S, Jawaharlal Nehru Medical College, Belagavi, Karnataka, India.

3. Physiotherapist, KAHER, Institute of Physiotherapy, Belagavi, Karnataka, India.

\section{Manuscript Info}

Manuscript History

Received: 25 July 2020

Final Accepted: 28 August 2020

Published: September 2020

Key words:-

Acute Sinusitis, Nadifloxacin

Phonophoresis, Pulsed Ultrasound,

Sinusitis Symptom Score, Numerical

Rating Scale, SNOT-22

\section{Abstract}

Aim: To find effectiveness of nadifloxacin phonophoresis over pulsed ultrasound in acute sinusitis subjects.

Methods: Study was approved by Institutional Ethical Committee of KAHER Institute of Physiotherapy, Belagavi.40subjects with acute sinusitis were divided randomly into group A, treated with nadifloxacin phonophoresis and group B, treated with pulsed ultrasound. Subjects were assessed using Sinusitis Symptom Score, Numerical Rating scale and Sino-nasal outcome test-22 before and after 4 days of intervention.

Result: For sinusitis symptom measure within the groups, mean difference were $6.16 \pm 1.97$ and $6.27 \pm 1.8$ with p-value of 0.001 for both the groups which was significant. For between the groups, $p$-value was 0.700 which was not significant. For numerical rating scale within the groups, mean difference was $0.37 \pm 0.14$. and $0.27 \pm 0.08$ with p-value of 0.001 for both the groups which was significant. For between the groups, p-value of 0.014 which was significant. For Sino nasal outcome test within the groups, mean difference was $16.33 \pm 9.55$ and $7.50 \pm 1.85$ with p-value of 0.001 for both the groups which was significant. For between the groups, $\mathrm{p}$-value was 0.001 which was significant.

Conclusion: Nadifloxacin phonophoresis was more effective than pulsed ultrasound in acute sinusitis.

Copy Right, IJAR, 2020,. All rights reserved.

\section{Introduction:-}

The function of the sinuses is to make the skull lighter and add resonance to the voice. ${ }^{1}$

Sinusitis refers to an inflammatory condition involving the four paired structures surrounding nasal cavities. The maxillary sinus is most commonly involved as compare to other paranasal sinuses. ${ }^{2}$ Theincidence of sinusitis in India is 10 millions cases per year. The most commonly isolated bacteria from maxillary sinuses are streptococcus pneumoniae and haemophillus influenza. ${ }^{2}$

Corresponding Author:- Anil Rachappa Muragod

Address:- Associate Professor, HOD of Geriatric Physiotherapy, KAHER, Institute of Physiotherapy, Belagavi, Karnataka, India. 
Acute sinusitis can be defined by certain major and minor criteria that exists for longer than typical viral upper respiratory tract infections, greater than 7 days. Major criteria includes purulent nasal discharge, purulent pharyngeal drainage,cough and minor criteria includes peri-orbital oedema, headache, facial pain, tooth pain, ear pain, sore throat, foul breath, increased wheeze and fever.

The presence of two major or one minor and two or more minor criteria for more than 7 days signifies acute sinusitis. ${ }^{4}$ The medical management includes the use of oral or topical decongestants, mucolytics, pain and fever management with NSAIDs and saline rinses provides maximum relief of symptoms. ${ }^{2}$ Surgical management is advised if the conditionis severe or if they have severe intracranial complications. ${ }^{2}$

\section{Demographic Data Distribution In Group A And Group B:}

\begin{tabular}{|c|c|c|c|c|c|c|c|}
\hline & \multicolumn{2}{|c|}{ GENDER } & AGE & BMI & \multicolumn{3}{|c|}{ p-value } \\
\hline Groups & $\begin{array}{l}\text { Male } \\
\text { (\%) }\end{array}$ & $\begin{array}{l}\text { Female } \\
(\%)\end{array}$ & Mean \pm SD & $\begin{array}{l}\text { Mean } \pm \\
\text { SD }\end{array}$ & Gender & Age & BMI \\
\hline Group A & $\begin{array}{l}33.3 \\
(6 / 18)\end{array}$ & $\begin{array}{l}66.7 \\
(12 / 18)\end{array}$ & $28.16 \pm 9.78$ & $25.06 \pm 3.57$ & 0.717 & 0.309 & 0.812 \\
\hline Group B & $\begin{array}{l}27.8 \\
(5 / 18)\end{array}$ & $\begin{array}{l}72.8 \\
(13 / 18)\end{array}$ & $25.44 \pm 6.91$ & $24.06 \pm 6.33$ & & & \\
\hline
\end{tabular}

The p-value of gender, age and BMI suggest that both the groups are homogeneous.

Physiotherapy management includes use of therapeutic ultrasound. The principle on which ultrasound works is piezoelectric effect. $^{5}$ The ultrasonic waves cause mechanical vibration within the affected sinuses and helps in mobilization of secretions. ${ }^{5}$

Phonophoresis is used as an alternative for transdermal drug delivery.It is advantageous because the rate and concentration of transport of drugs to the affected paranasal sinuses is enhanced. ${ }^{6}$

\section{Need for the study:}

The use of pulsed ultrasound is proven to be effective for acute sinusitis whereas there is paucity in the literature to support use of phonophoresis in acute sinusitis subjects, thus the need arise to compare the effectiveness of phonophoresis over ultrasound.

\section{Methodology:-}

Methods: Forty subjects with acute sinusitis were recruited from tertiary health care centre, out of which 4 subjects were unable to follow up.

\section{Inclusion criteria:}

Subjects clinically diagnosed with acute sinusitis, Age group between 18-50 years,Both male and female subjects willing to participate in the study.

\section{Exclusion criteria:}

Prostheses or metal implant in the brain, face, or orbit, dental implants, Other infection on the face, Obstruction for the free drainage of the sinuses, Pregnant women, Malignancy of head and neck

\section{Procedure:}

The study was approved by Institutional Ethical Committee of KAHER Institute of Physiotherapy, Belagavi.

\section{Intervention:}

The subjects diagnosed with acute sinusitis were recruited in the study after screening for the inclusion and exclusion criteria. They were randomly divided into group A, who received nadifloxacin phonophoresis and group $\mathrm{B}$, who received pulsed ultrasound. In group A, the position of the subject is supine lying and therapist is standing on the side to be treated. The treatment is begun with applying nadifloxacin ointment with aqueous gel on the treatment area. Pulsed mode of ultrasound was chosen where the intensity was $0.5 \mathrm{~W} / \mathrm{cm}^{2}$ with ratio of $1: 4$ and frequency of $1 \mathrm{MHz}$ and $20 \%$ duty cycle. ${ }^{7}$ Duration of treatment was 5 minutes for maxillary sinus and 4 minutes for frontal sinus for 4 days a week. ${ }^{7}$ Group B received PUS with aqueous gel and Dosage was the same as described 
above for group A. Sinusitis Symptom Score, Numerical Rating scale and Sino-Nasal Outcome Test-22 were the outcome measures assessed pre and post treatment on $4^{\text {th }}$ day.

Results:-

\begin{tabular}{|c|c|c|c|c|}
\hline Groups & Time Frame & Mean \pm SD & Mean Diff \pm SD Diff & \multicolumn{2}{|c|}{ p-value } \\
\hline \multirow{2}{*}{ Group A } & Pre-test & $10.77 \pm 3.20$ & $6.16 \pm 1.97$ & 0.001 \\
\cline { 2 - 5 } & Post-test & $4.61 \pm 1.81$ & & 0.700 \\
\cline { 2 - 4 } Group B & Pre-test & $10.22 \pm 2.66$ & $6.27 \pm 1.80$ & 0.001 \\
\hline
\end{tabular}

Comparison of Group A And Group B Within And Between The Groups With Respect To Sinusitis Symptom Score

In the present study the $\mathrm{p}$-value for both the groups was 0.001 which suggests that it is significant whereas the $\mathrm{p}$ value of difference between the groups was 0.700 which was not significant but both groups were equally effective.

Comparison Of Group A And Group B Within And Between The Groups With Respect To Numerical Rating Scale:

\begin{tabular}{|c|c|c|c|c|}
\hline Groups & Time Frame & Mean \pm SD & Mean Diff \pm SD Diff & \multicolumn{2}{|c|}{ p-value } \\
\hline \multirow{2}{*}{ Group A } & Pre-test & $0.60 \pm 0.16$ & $0.37 \pm 0.14$ & 0.001 \\
\cline { 2 - 5 } & Post-test & $0.22 \pm 0.10$ & & 0.014 \\
\cline { 2 - 5 } Group B & Pre-test & $0.52 \pm 0.17$ & $0.27 \pm 0.08$ & 0.001 \\
\hline
\end{tabular}

In the present study the $\mathrm{p}$-value for both the groups was 0.001 which suggests that it is significant whereas the $\mathrm{p}$ value of difference between the groups was 0.014 which is significant and suggests that group A is better than group B

\begin{tabular}{|l|l|l|l|l|l|}
\hline Groups & Time Frame & Mean \pm SD & $\begin{array}{l}\text { Mean Diff } \pm \text { SD } \\
\text { Diff }\end{array}$ & \multicolumn{2}{|l|}{ p-value } \\
\hline \multirow{2}{*}{ Group A } & Pre-test & $36.00 \pm 13.47$ & $16.33 \pm 9.55$ & 0.001 \\
\cline { 2 - 4 } & Post-test & $18.94 \pm 5.88$ & & 0.001 & 0.001 \\
\cline { 1 - 3 } Group B & Pre-test & $26.44 \pm 6.21$ & $7.50 \pm 1.85$ & & \\
\cline { 2 - 3 } & Post-test & $18.94 \pm 5.88$ & & 0.01 \\
\hline
\end{tabular}

Comparison of Group A And Group B Within And Between The Groups With Respect To Snot-22

In the present study the p-value for both the groups was 0.001 and the p-value of difference between the groups was also 0.001 which suggests that it is significant and suggests that group $\mathrm{A}$ is better than group B

\section{Discussion:-}

Sinusitis symptom score was used as one of the outcome measure in our study and it was observed that this outcome measure did not prove to be effective. The reason being that the patients scored zero for few symptoms and according to a study conducted it is proven that the scores should not be zero or near zero following treatment but rather it should be closer to the values scored by healthy individuals. ${ }^{8}$

Numerical rating scale was another outcome measure used in our study to rate the facial pain and it was observed that subjects rated facial pain in a better way and found relief post-treatment. Previous study conducted used numerical rating scale to rate pain and congestion due to rhinosinusitis and it was observed that there was reduction in pain around the nose by 1.5 points out of 10 post-intervention. ${ }^{9}$ The outcome measure SNOT-22 was effective in the current study as it showed marked reduction in all the domains of the test after the treatment sessions. A study conducted in patients having facial pain and sleep disturbances due to chronic sinusitis suggests that SNOT-22 was the only outcome measure that assesses interference in the sleep patterns and reports about the improvement in sleep patterns and other symptoms of sinusitis post-intervention. ${ }^{10}$ 
In the present study the limitations were: Inability to treat ethmoid and sphenoid sinuses, Long term follow up could not be achieved and recurrence of symptoms could not be noted, Subjects with other co-existing infections in the head and neck region could not be treated.

Future scope of this study is: Exploration of more drugs for phonophoresis in sinusitis, studying the effects of phonophoresis in recurrent cases of sinusitis.

\section{Conclusion:-}

The present study concluded that both, nadifloxacin phonophoresis and pulsed ultrasound are effective in the treatment of acute sinusitis but comparatively, nadifloxacin phonophoresis is more effective than pulsed in acute sinusitis.

\section{References:-}

1. Chaurasia B. B D Chaurasia's human anatomy regional and applied, dissection and clinical volume 3. 6th ed. New Delhi: CBS Publishers; 2004.

2. Jameson J, Fauci A, Kasper D, Hauser S, Longo D, Loscalzo J et al. Harrison's principles of internal medicine. The McGraw-Hill Companies; 2018

3. According to statistics (Aug.2016), Sinusitis is a very common condition and accounts for more than 10million cases per year in India,- www.google.co.in/search?q=Sinusitis TOI, PratibhaMasand |TNN |Apr 11,2012,12.14 AM IST

4. Shapiro GG, Rachelefsky GS. Introduction and definition of sinusitis.Journal of Allergy and Clinical Immunology. 1992 Sep 1;90(3):417-8.

5. Robertson V, Low J, Reed A, Ward A. Electrotherapy explained. 4th ed. Edinburgh: Butterworth-Heinemann Elsevier; 2006.

6. Ansari NN, Naghdi S, Fathali M, Bartley J, Rastak MS. A randomized clinical trial comparing pulsed ultrasound and erythromycin phonophoresis in the treatment of patients with chronic rhinosinusitis.Physiotherapy theory and practice. 2015 Apr 3;31(3):166-72.

7. Ansari NN, Fathali M, Naghdi S, Bartley J, Rastak MS. Treatment of chronic rhinosinusitis using erythromycin phonophoresis. Physiotherapy theory and practice. 2013 Feb 1;29(2):159-65.

8. Walker FD, White PS. Sinus symptom scores: what is the range in healthy individuals?. Clinical Otolaryngology \& Allied Sciences. 2000 Jun;25(6):482-4

9. Høsøien E, Lund AB, Vasseljen O. Similar effect of therapeutic ultrasound and antibiotics for acute bacterial rhinosinusitis: a randomised trial. Journal of physiotherapy. 2010 Jan 1;56(1):27-32.

10. Smith M, Berenger P, Bonutti P, Ramakrishnan A, Beyers J, Ramakrishnan V. Multimodal Frequency Treatment for Facial Pain Caused by Chronic Rhinosinussitis: A Pilot Study. Sinusitis. 2017;2(3). 